University of Texas Rio Grande Valley

ScholarWorks @ UTRGV

\title{
Wrap-around services to older adults with dementia: collaboration, education, and prevention as a model for integration of primary care and neurobehavioral health
}

\author{
Gladys E. Maestre \\ The University of Texas Rio Grande Valley, gladys.maestre@utrgv.edu \\ Francisco Fernandez \\ The University of Texas Rio Grande Valley, francisco.fernandez@utrgv.edu
}

Follow this and additional works at: https://scholarworks.utrgv.edu/som_pub

Part of the Medicine and Health Sciences Commons, and the Neuroscience and Neurobiology Commons

\section{Recommended Citation}

Maestre, G. E., \& Fernandez, F. (2019). WRAP-AROUND SERVICES TO OLDER ADULTS WITH DEMENTIA: COLLABORATION, EDUCATION, AND PREVENTION AS A MODEL FOR INTEGRATION OF PRIMARY CARE AND NEUROBEHAVIORAL HEALTH. Alzheimer's \& Dementia, 15(7, Supplement), P205. https://doi.org/ 10.1016/j.jalz.2019.06.4543

This Conference Proceeding is brought to you for free and open access by the School of Medicine at ScholarWorks @ UTRGV. It has been accepted for inclusion in School of Medicine Publications and Presentations by an authorized administrator of ScholarWorks @ UTRGV. For more information, please contact justin.white@utrgv.edu, william.flores01@utrgv.edu. 


\section{Wrap-around services to older adults with dementia: collaboration, education, and prevention as a model for integration of primary care and neurobehavioral health}

Gladys E. Maestre

Francisco Fernandez

\section{Background}

Medical care in the Rio Grande Valley (RGV) is fragmented and difficult to navigate, especially for older adults with cognitive decline and dementia. The communities are eager to have a new healthcare delivery system that integrate community-based aging services to provide integrated, team collaborative better health care in our communities. The University of Texas RGV School of Medicine, in collaboration with its affiliates in the regional healthcare systems, is a partner providing comprehensive care across the life-cycle bridging science, social services and patient care. Our interprofessional team collaborative emphasizes safe, appropriate, and effective neurobehavioral care, employing evidence-based medicine in collaboration with the patient's preferences and culture.

\section{Methods}

Different strategies are being deployed to create, enhance and target system-wide cross-organisational care pathways to support persons with dementia (PwD) and their caregivers. The initial focus of integration is the referral network management (inter-organizational care pathways). Additional mechanisms for care integration are the use of a mobile community health integrative care hub to improve access and prevention in the South Texas Colonias; a dedicated program for older adults care that may be triply diagnosed (general-neuro-behavioral); and, an innovative curriculum to achieve improvements in population health outcomes through AD-RCMAR programs emphasizing collaboration and prevention.

\section{Results}

Small-scale testing has revealed that multidisciplinary teams, both within and across organizations, emerged as the most important single care coordination mechanism. Operationally this translates in identification of tasks and roles and in the agreement over one overall care plan per patient, not defined by each profession but patient-centered. Different barriers to integration include those related to IT infrastructure and limited access to services due to 'gatekeeping' rules that determine referral capabilities and geographical isolation.

\section{Conclusions}


Wrap-around services to older adults with dementia are expected to have a direct impact on the care of the patients and families in the RGV and to be associated with better health outcomes and better satisfaction for all. A better understanding of factors determining integration is needed in order to develop more cost-effective pathways of care for PwD and their caregivers. Funding: National Institutes of Health, National Institute of Aging 1 P30 AG059305-01. 